\title{
Conceptual Approach to Understanding and Exploring the Cultural meaning of Computer according to Jeffrey
}

\author{
Alexander $^{1}$
}

\author{
Badri Borandegi \\ PhD Student of Sociology in University of Isfahan, Department of Social Sciences \\ Email: b_borandegi@yahoo.com,
}

\begin{abstract}
Ali Rabbani
Associate Professor and faculty member of social science group in university of Isfahan Email: a.rabbani@1tr.ui.ac.ir,
\end{abstract}

Doi:10.5296/jsr.v5i1.5944 URL: http://dx.doi.org/10.5296/jsr.v5i1.5944

\begin{abstract}
Human phenomena are Significant and all works that are created by humans can carry meaning. These meanings are cultural constructs. Understanding of these meanings is the task of cultural sociology. The main goal of the cultural sociology is to show aspects of the collective unconsciousness. This result is based on unconscious cultural structures that lead society to the ideas of the Enlightenment. However, the process of understanding may change, but the structure does not break apart because Society cannot survive without these structures. In this research, we ask one question: "what is cultural meaning of Computer based on cultural sociology theory of Jeffrey C. Alexander"? This study seeks to determine the cultural meaning of computer with Knowledge and method of cultural sociology; also we try to understand symbols, codes and narratives about computer according to Alexander.

According to Alexander, computers were coded as good or sacred since its entry into the west public sphere and were presented the good narrative from it, such as salvation narrative, eschatology narrative and Apocalypse narrative. But gradually, the good times ended and the dark side of the computer crash on human and romantic story with computer showed its pathological aspects. Gradually the cultural meaning of computer was different in social life in the West. Computers were coded as an aspect of evil. Population gradually saw the computers as unholy or profane. Computers became the Frankenstein monster in West.
\end{abstract}

Keywords: Computer, Cultural Sociology, Jeffrey Alexander, structural hermeneutics

\footnotetext{
${ }^{1}$ Extracted from $\mathrm{PhD}$ thesis with title: “The Cultural Meaning of Computer in Iranian's Social Life: from 1991 to 2011 AD”
} 


\section{Mll Macrothink}

\subsection{Introduction}

Historical evidence indicates that humans have always paid attention to meaning and its understanding a long time ago. The concept of meaning has had wide changes in history and its extent and conceptual space has been extended. Apart from the ontological level, human has lived in various communities during the history, and it required the exchange of messages with other fellows. The requirement has not a distance to focus on meaning and understanding meaning because the meaning is part of each message and understanding meaning is most basic two-way interaction of any communication. From the perspective of ontology, human beings are meaning-creators. With a little tolerance, this claim is a restatement of the old definition of man as a "rational animal". Dilthey argues human phenomena have meaning and all works created by humans can carry meaning. Weber also argues that human and social phenomena have meaning inside, while natural phenomena are mean outside and actually meaning is shipped by them. Methodological consequences of these ontological claims about human nature, human and social realities are in the analysis of the human and social phenomena that should try to discover hidden meanings (verstehen), but identifying causal relationships is originality in the analysis of natural phenomena (explanation) (kalantari, 2007: 101- 102).

Assessment of the meaning or message of any cultural object is relatively much harder. Cultural object is substantive and has rich content and is difficult to interpret or read (Hall and Jo Neitz, 1993: 321). In one of the works of Clifford Geertz, culture is seen as a symbolic form that is available to the public and people experience and express meaning through it. Extraordinary analysis of Geertz proposed a new definition of culture (Hall and Jo Neitz, 1993: 359). Material can be an aspect of culture, but only when the meaning is ascribed for them (Hall and Jo Neitz, 1993: 360).

According to Coser (1971), a phenomenon is not inherently secular or sacred, but it finds one of these two characteristics when people distinguish utilitarian value for the phenomenon or rather, traits attributed to it do not have any relationship with their worth (Coser, 1971: 198). According to Durkheim, the origin of religion is society. Society knows something as religious and some other things profane (Ritzer, 1983: 23).

Traditional approaches to meaning in sociology treat culture as a dependent variable; only social power, social structures, and material interests are treated as independent variables that have a causal status. In this manner, sociology turns from culture to its unmoved mover, "society" as a noncultural force. Thus is the social reduction of politics camouflaged in cultural form (Alexander, 2010: 282).

Jeffrey Alexander (1998) argues that Durkheim's analysis of rituals in ancient religions is an example for understanding how symbolic processes act on their own terms. Durkheim considers the causal importance of autonomy for symbolic classification through the distinction of sacred/profane in elementary forms of religious life and shows the close relationship between the processes of ritual and formation of social cohesion. According to Alexander, the value of this work is to design an example - " religious form of ultra-progressive experience" - that is for "certain general processes" (Hall and Jo Neitz, 1993: 98).

Durkheim considered the dichotomy between the sacred and the profane to be the central 
characteristic of religion: "religion is a unified system of beliefs and practices relative to sacred things, that is to say, things set apart and forbidden." In Durkheim's theory, the sacred represented the interests of the group, especially unity, which were embodied in sacred group symbols, or totems. The profane, on the other hand, involved mundane individual concerns. Durkheim explicitly stated that the dichotomy sacred/profane was not equivalent to good/evil. The sacred could be good or evil and the profane could be either as well (Durkheim, 1912: 49).

Modernity has eliminated neither deep meaning nor encrusted tradition; it has, rather, changed the content of meaning and multiplied its forms. Modern culture still provides anchoring codes and narratives even if they often evoke rationality, individuality, skepticism, and social transformation more often than mystery, hierarchy, stasis, and metaphysical belief. As far as the role of meaning goes, according to Durkheim, no irrevocably great divide exists between the aboriginals who believed in totemic gods and "the religious man of today." Modern people still engage in emotional and ritual action, energizing symbols that can become powerful collective representations, dividing the sacred from profane (Alexander, 2010: 282).

These rhetorics are cultural structures. They are deeply constraining but also enabling at the same time. The problem is that we don't understand them. This is the task of a cultural sociology. It is to bring the unconscious cultural structures that regulate society into the light of the mind. Understanding may change but not dissipate them, for without such structures society cannot survive. According to Alexander (2003: Introduction) we need myths if we are to transcend the banality of material life. We need narratives if we are to make progress and experience tragedy. We need to divide the sacred from profane if we are to pursue the good and protect ourselves from evil.

Of course, social science has always assumed that men and women act without full understanding. Sociologists have attributed this to the force of social structures that are "larger" and more "powerful" than mere individual human beings. They have pointed, in other words, to the compulsory aspects of social life. But what fascinates and frightens Alexander are those collective forces that are not compulsory, the social forces to which we enthusiastically and voluntarily respond. Cultural sociology is a kind of social psychoanalysis. Its goal is to bring the social unconscious up for view.

The computer is the newest and one of the most potent technological innovations of the modern age. The gradual permeation of the computer into the pores of modern life deepened what Max Weber called the rationalization of the world. The computer converts every message, regardless of its substantive meaning, metaphysical remoteness, or emotional allure, into a series of numerical bits and bytes. These series are connected to others through electrical impulses. This is the subjection of worldly activity to impersonal rational control and more forceful illustration of the disenchantment of the world that Weber warned would be the result. Thus we are not only trapped inside of Weber's cage of iron but also bound by the laws of exchange that Marx asserted would eventually force everything human into a commodity form (Alexander, 2003: chapter 7).

Considered in its social reference-its economic and scientific forms-technology is a thing that can be touched, observed, interacted with, and calculated in an objectively 
rational way. Analytically, however, technology is also part of the cultural order. It is a sign, both a signifier and a signified. The modern world is indeed technological, but technology is hardly purely material in form. It is religion and antireligion, our god and our devil, the sublime and the accursed. Technology is rooted in the deepest resources and abysses of our imagination (Alexander, 2003: 179). In this paper, we study the cultural meaning of computer from the perspective of Alexander as a cultural sociologist.

\subsection{Cultural Sociology}

Formation of cultural sociology within the sociology of culture and after the developments has been known the "cultural turn" began in the mid 1985's as a distinct approach to the sociology of culture and cultural studies (Nabavi, 2012: 3 and 27).

Since 1998, the 'new American cultural sociology' has emerged as a significant and confident intervention, designed to re-orientate sociology and cultural studies alike in quite fundamental ways. The sociological theorist Jeffrey Alexander stands at the center of this development, and it is his work, especially his recent writings. The scale and coherence of Alexander's project are indicated by the fact that it operates on four interconnected levels of abstraction. The first of these is Alexander's rendering of post-positivism as the necessary philosophical framing for all social enquiries at the present time, and the second, couched within this frame, is his configuration of the project of cultural sociology. The third aspect is the embodiment of the theoretical platform in a series of substantive analyses, while the fourth features Alexander's thinking about the cultural politics of contemporary civil society (McLennan, 2005: 1).

Cultural sociology incorporates into its fold elements of structuralist and semiotically-inspired literary criticism and social anthropology. This enables Alexander to demonstrate that, instead of being random or fully spontaneous phenomena, symbolically and discursively mediated significations are congealings of social interactions and institutionalized processes structured by and themselves structuring regularized meaning-producing scripts and typifications: narrative frames and genres, and binary codes (good/evil, pollution/purity, sacred/profane, etc.). (Kurasawa, 2004: 54).

In a neo-Kantian mode but in Dilthey's and Weber's historicizing spirit, Alexander has done so by insisting that culture is a dimension of all action, not a variable that stands off to one, even if very important, side. Culture is analytically autonomous, even if, in every concrete empirical moment, it is part of a multidimensional and complex whole. Alexander tried to reconstruct the culture/structure vocabulary of classical and modern sociology. Incorporating semiotics and poststructuralism, he tried to develop something new, a cultural sociology. He has also developed this structures-within-culture approach through a series of critical hermeneutic encounters, or readings (Alexander, 2005: 21).

The ambition of cultural sociology has been to open up this black box, to provide the internal architecture of social meaning via concepts of code, narrative and symbolic action, so that culture can finally assume its rightful place as equivalent to, and interpenetrated with, other kinds of structuring social force. Alexander has developed this internal architecture by incorporating and reinterpreting certain central aspects of the late Durkheim, phenomenology and micro-sociology, symbolic anthropology, structuralist semiotics, narratology, 
post-structuralism and deconstruction. Yet, even while elaborating the architecture of culture structure, Alexander has tried not to lose sight of the broader aim, which is to theorize society as a whole (Alexander, 2005: 22).

What cultural sociology produces, rather, are reconstructions of social meaning. These interpretations, moreover, are guided by strong theoretical claims about the nature and interrelation of symbolic forms, and their relation to social life. Cultural sociology makes claims about social causes, identifies individual and collective actors as agents, and takes into account mediating hierarchies and institutions (Alexander, 2005: 27).

Cultural sociology is a broad and powerful new movement, not only in the United States but beyond it as well. New theoretical movements challenge vested intellectual interests. Cultural sociology insists on the ideal power of material interests, and the material power of ideal interests (Alexander, 2005: 19).

Cultural sociology is different from cultural studies in some aspects. Alexander's cultural sociology approach is typical of shaping the aesthetic concept of culture within the sociology of culture after "cultural turn". Within the theoretical developments after the event, the fundamental issues of structure, agency, realism or constructionism, system and differences have been considered and have caused the formation of certain attitude toward culture. Jacobs and Weiss Hanrahan write in introduction to the book "Guide to the Sociology of Culture": "culture is understood differently in terms of discourses, actions, meaning, performances, and boundaries and general frameworks, as well as in terms of values, norms, and systems" (Jacobs and Weiss Hanrahan, 2005: 10). Alexander's cultural sociology has tried to combine and mix the various ways according to multidimensional policies that he sees.

\subsection{Jeffrey Alexander and Cultural sociology}

Alexander was a cultural Marxist (Cordero, Carballo and Ossandón, 2008: 524) but he gradually turned away from cultural Marxism and focused on the works of Durkheim later. In an interview with Jalaeipour, Alexander explains that "principally, cultural sociology that I have designed, in fact, is evolved version of Durkheim (Durkheim later)" (Jalaeipour and mohammadi, 2008: 459).

Integrating and combining of hermeneutics and structuralism as a multi-dimensional approach, review other sociological theories of culture and in accordance with a development plan that he referred to Parsons and "new fundamentalism" forms a step in theorizing of cultural sociology that achieves to certain perception of culture epistemologically and methodologically (Nabavi, 2012: 36).

Alexander and Smith have written a paper in 2002: "THE STRONG PROGRAM IN CULTURAL SOCIOLOGY: Elements of a Structural Hermeneutics". They explain the fault line. The fault line at the heart of current debates lies between "cultural sociology" and the "sociology of culture".

In his view, the belief in cultural sociology is acceptance of this idea that every action (whether instrumental, reflexive and mandatory) is given in the horizons of meaning and impact rather than its external environment. The internal environment is an environment where actors cannot be instrumental or reflexive to it. The internal environment is an ideal source that limit and possible action somewhat and "a belief in the possibility of cultural 
sociology implies that institutions have an ideal foundation and foundation that form their organization and goals fundamentally and provide a structured context for the debate over their legitimacy" (Alexander and Smith, 2002: 136). In other words, in his opinion, cultural sociology examines the structures within the meaning and emphasis that the meaning and value are intertwined to all other processes and we cannot say nonculture thing is cause of the cultural thing and vice versa (Jalaeipour and Mohammadi, 2008: 46).

Alexander gives an independent place to culture and meaning. To do this, he applies a conceptual tool in the social studies of science that has been developed recently. It means "strong program" for "detailed and clear analytical separation of culture and social structure" in the sociological study of culture.

According to him, sociologists are able to explain "powerful role that culture plays in shaping social life" only through strong program. According to him, commitment to "socio-cultural theory" to require self-organization and autonomy of culture is considered as the single and most important feature of a strong program. The approach of Alexander's cultural sociology involves two other features. First, the "responsibility to reconstruct social texts" is practical through "deep Geertz describes the codes, narratives, and symbols that make up the social meaning" and this requires putting outside parentheses of the non-symbolic relations to achieve culturally pure text and deep Geertz describes. He refers to Paul Ricoeur's argument about the necessity of the link between interpretation and semiotics and says that reconstruct of cultural pure text can be considered as a "cultural construct" and to be studied as a social text. Another feature of the strong program is to "stabilize causation directly on the actors and agency" (Alexander and Smith, 2002: 136).

Alexander and Smith pose the idea of strong program in cultural sociology as "overtly polemical", while they claim that it offers "a certain style of theory" and "the best way towards a cultural sociology" (Alexander and Smith, 1993: 12). Culture is understood relatively independent of cultural structures, institutional relations of power and etc. (Smith, 2004: 66).

Alexander and Smith wrote in Handbook of Cultural Sociology (2010) that strong program is one of the most controversial debates in the cultural turn in sociology. For them, strong program is a research program with a series of models, methods and conceptual tools that individually or together, are allowed to interpret and explain the social world. According to Alexander and Smith (2010: 13), although we see strong program as an important sociological period of cultural turn, its ideas have continued into the twentieth century. Wittgenstein's philosophy of language emerged in the 1940s and 1950s. French structuralists and semioticians peaked in 1950s and 1960s. Cultural anthropologist such as Douglas, Turner and Geertz wrote their influence works in the mid-1960s to early 1970s. These authors have used selected texts of Durkheim and Weber and are ready mental foundation for strong program.

In their formulation of "the "strong" program in cultural sociology' Jeffrey C. Alexander and Philip Smith state that sociology 'for most of its history' has been dominated by 'culturally unmusical scholars'. In trying to understand the transformations and crises of modern society sociologists 'emptied' rather than focused 'the world of meaning'. Even if there were glimmers from the classics, sociology, both as theory and method, came to suffer 'from a 
numbness toward meaning' (Trondman, 2008: 202).

Geertz tried more than anyone in this field (Geertz, 1999: 10). After four decades, cultural analysis if Geertz by Alexander and Smith referred to as a springboard to a strong program in cultural analysis (Alexander, 2003: 22). In October 2007, the Center for Cultural Sociology at Yale University was invited researchers, theorists and empirical researchers from different disciplines to think about "Geertz" future-oriented and critically. Alexander says they all agreed that Geertz is important in the half of last century in the humanities (Alexander, 2008: 158).

\subsection{The method of cultural sociology}

The philosophical principles for this hermeneutic position were articulated by Dilthey (1962), and it seems to us that his powerful methodological injunction to look at the "inner meaning" of social structures has never been surpassed. Rather than inventing a new approach, the deservedly influential cultural analyses of Clifford Geertz can be seen as providing the most powerful contemporary application of Dilthey's ideas. In methodological terms, the achievement of thick description requires the bracketing-out of wider, nonsymbolic social relations. This bracketing-out, analogous to Husserl's phenomenological reduction, allows the reconstruction of the pure cultural text, the theoretical and philosophical rationale for which Ricoeur (1971) supplied in his important argument for the necessary linkage between hermeneutics and semiotics. This reconstruction can be thought of as creating, or mapping out, the culture structures (Rambo \& Chan, 1990) that form one dimension of social life. It is the notion of the culture structure as a social text that allows the well-developed conceptual resources of literary studies - from Aristotle to such contemporary figures as Frye (1971, [1957]) and Brooks (1984) — to be brought into social science. Only after the analytical bracketing demanded by hermeneutics has been completed, after the internal pattern of meaning has been reconstructed, should social science move from analytic to concrete autonomy (Kane, 1992). Only after having created the analytically autonomous culture object does it become possible to discover in what ways culture intersects with other social forces, such as power and instrumental reason in the concrete social world (Alexander, 2003: chapter1).

If Dilthey is Inspiration for Alexander to claim priority methodology of culture, a central design that helps sociology stand on the bones of hermeneutics is derived from Durkheim: "Culture should be understood as a system of symbolic codes that defines good and evil" (Alexander and Smith, 1993: 196). Alexander's works about the binary of good and evil is partly theoretical and partly practical, engaging duality the sacred / profane and clean / contaminated.

According to Alexander (2003: Chapter 4), when we are facing with the seemingly powerful natural phenomenon like evil, we need a strong dose of the social construction to see what is going on. Specifically, we need to examine the code and good and evil (Alexander, 2003: 115).

The line dividing the sacred from profane must be drawn and redrawn time and time again. Through such phenomena as scandals, moral panics, public punishments, and wars, societies provide occasions to reexperience and recrystallize the enemies of the good. According to 
Alexander, the structural hermeneutic can construct meanings that are core of the social life. Only after such reconstruction, we can analyze relationship between "cultural structures" and social power in its political and economic forms (Alexander, 2007: 24).

The interpretation of the show presented here broadly follows the structural hermeneutic theory developed by Alexander and Smith in the context of cultural sociology. They write that, "Structuralism and hermeneutics can be made into fine bedfellows. The former offers possibilities for general theory construction, prediction and assertions of the autonomy of culture. The latter allows analysis to capture the texture and temper of social life (Norton, 2011: 318).

Holding structural hermeneutics together is a performative and dramaturgical vision of social life that, here again, builds upon literary and anthropological sources to underscore the cultural significance of ritual action and mythical conventions (Kurasawa, 2004: 55).

For cultural sociology, the meaning of an event or phenomenon is constructed over time through three processes: narrative framing (how are the various elements of this event or phenomenon regrouped, positioned and incorporated into a larger plotline or story?); symbolic coding (how is it classified according to binary affective and moral codes?); and weighting (what resources are brought to bear in its construction and dissemination?). Because persons, groups or occurrences must be coded and become perceived as evil, polluted or sacred, rather than being inherently so, the attribution of specific emotion- and value-laden signifiers to any social signified is a cultural process of meaning construction (Kurasawa, 2004: 56). We attempt in this paper to examine cultural meaning of computer from the perspective of Alexander.

\subsection{The computer according to Alexander}

According to Alexander (2003: Chapter 7), the oldest prejudice that social theory has held about modern life is that it is not prejudiced at all. Modernity will make people rational because it is scientific, and because it is so scientific, the institutions of and processes of modern society have become "purely technological." This venerable story can be pessimistic or optimistic, but it is always anticultural, for it stresses the utter materialism of the contemporary world. But this is a just-so story. The modern world is indeed technological, but technology is hardly purely material in form. It is religion and antireligion, our god and our devil, the sublime and the accursed.

Considered in its social reference-its economic and scientific forms - technology is a thing that can be touched, observed, interacted with, and calculated in an objectively rational way. Analytically, however, technology is also part of the cultural order. It is a sign, both a signifier and a signified, in relation to which actors cannot entirely separate their subjective states of mind. Social scientists have not usually considered technology in this more subjective way. Indeed, they have not typically considered it as a cultural object at all. It has appeared as the material variable par excellence, not as a point of sacrality but as the most routine of the routine, not a sign but an antisign, the essence of a modernity that has undermined the very possibility for cultural understanding itself.

Alexander said we must learn to see technology as a discourse, as a sign system that is subject to semiotic constraints even as it is responsive to social and emotional demands. The 
first step to this alternative conception of modern technology is to reconceptualize its historical emergence in metaphysical terms.

According to Alexander, expectations for salvation were inseparable from the technological innovations of industrial capitalism. Major inventions like the steam engine, railroad, telegraph, and telephone were hailed by elites and masses as vehicles for secular transcendence. Their speed and power, it was widely proclaimed, would undermine the earthly constraints of time, space, and scarcity.

In their early halcyon days, they became vessels for experiencing ecstatic release, instruments for bringing the glories of heaven down to earth. The technicians and engineers who understood this new technology were elevated to the status of worldly priests. In this technological discourse, however, the machine has been not only God but also the devil. In the early nineteenth century, Luddites lashed out at spinning machines as if they were the idols that the Hebrew fathers had condemned. William Blake decried "dark Satanic mills." Mary Shelley wrote Frankenstein, or, the Modern Prometheus, about the terrifying results of Victor Frankenstein's effort to build the world's most "gigantic" machine. The gothic genre presented a revolt against the Age of Reason and insisted that dark forces were still brewing, forces that were often embodied by the engine of technology itself. It was, ironically, from such forces that the modern age had to be saved. There is a direct line from that gothic revival to George Lukas's wildly popular movie Star Wars. Today's science fiction mixes technology with medieval gothic themes, pits evil against good, and promises salvation from space, from time, even from mortality itself.

Within the conventional sociology-of-culture mind-set, Alexander maintains, computer technology constitutes a quintessential expression of instrumental rationality, inviting its analytical placement within a disenchanted world of systemic and material forces. Marx, Weber and Habermas can all be seen to invest in this thematic. But, far from driving meaning and values out of the social and cultural systems, new technology is coded in much contemporary experience as magical, awesome and sacred. Clearly, though, there is a good deal here that rings true. Relentless high-tech innovation is simultaneously fantastically powerful and beneficial, and yet also monstrous and destructive (McLennan, 2005: 6- 7).

Researches of Alexander (2003, Chapter 7) follow codes and narratives and suggest that this social meanings explain social effects of computer.

Alexander (2003) said the gradual permeation of the computer into the pores of modern life deepened what Max Weber called the rationalization of the world. The computer converts every message, regardless of its substantive meaning, metaphysical remoteness, or emotional allure, into a series of numerical bits and bytes. These series are connected to others through electrical impulses. Eventually these impulses are converted back into the media of human life.

Alexander asked can there be any better example of the subjection of worldly activity to impersonal rational control? Can there be any more forceful illustration of the disenchantment of the world that Weber warned would be the result? Much depends on the answer to this portentous question, for discourse about the meaning of advanced technology demarcates one of the central ideological penumbras of the age. If the answer is yes, we are not only trapped inside of Weber's cage of iron but also bound by the laws of exchange that 
Marx asserted would eventually force everything human into a commodity form.

The computer is the newest and certainly one of the most potent technological innovations of the modern age, but its symbolization has been much the same. The culture structure of technological discourse has been firmly set. Then, using cultural sociology, we study cultural meaning of computer according to Alexander.

While there were certainly routine assessments of the computer from 1944 to 1975-assessments that talked about it in rational, scientific, and "realistic" tones-they paled in comparison to the transcendental and mythical discourse that was filled with wish-fulfilling rhetoric of salvation and damnation. This sacred status was elaborated in the years that followed.

According to Alexander (2003), to be sacred, an object must be sharply separated from contact with the routine world. Popular literature continually recounted the distance that separated the computer from the lay public and the mystery attendant on this. Twenty years later the image had not changed.

Objects are isolated because they are thought to possess mysterious power. The connection between computer and established centers of charismatic power is repeated constantly in the popular literature. Occasionally, an analogy is made between the computer and sacred things on earth. If an object is sacred and sealed off from the profane world, gaining access to its powers becomes a problem in itself. The identification of the computer with God and of computer operators with sacred intermediaries signifies culture structures that had not changed in forty years.

The contact with the cosmic computer that these technological priests provided would, then, certainly transform earthly life. Like the revolutionary technologies that preceded it, however, the computer embodied within itself both superhuman evil and superhuman good. As Lévi-Strauss (1963) emphasized, it is through naming that the cultural codes defining an object are first constructed. In the years immediately following the introduction of the computer, efforts to name this new thinking machine were intense, and they followed the binary pattern that Durkheim and Lévi-Strauss described.

The result was a similitude of signifiers, an amplified series of sacred and profane associations that created for technological discourse a thick semantic field. One series revealed dreadful proportions and dire implications. The computer was called a "colossal gadget", a "figure factory", a "mountain of machinery", a "monster", a "mathematical dreadnought", a "portentous contrivance", a "giant", a "math robot", a "wonderworking robot", the "Maniac", and the "Frankenstein-monster".

In direct opposition to this profane realm, journalists and technicians also named the computer and its parts through analogies to the presumptively innocent and assuredly sacred human being. It was called a "super-brain" and a "giant brain". Attached to an audio instrument, it was described as "a brain child with a temporary voice" and as "the only mechanical brain with a soft heart". Its "physiology became a topic of debate. Computers were given an "inner memory", "eyes," a "nervous system", a "spinning heart", and a "female temperament" in addition to the brain with which they were already endowed. It was announced that they were to have "descendants, and in later years "families" and "generations" emerged. 


\section{Mll Macrothink}

Journal of Sociological Research

ISSN 1948-5468

2014, Vol. 5, No.1

The period of compulsive naming quickly abated, but the awesome forces for good and evil that the names symbolized have been locked in deadly combat to this day. Salvation rhetoric overcomes this dualism in one direction, apocalyptic rhetoric in another. Both moves can be seen in structural terms as overcoming binary opposition by providing a third term. But more profound emotional and metaphysical issues are also at stake. Computer discourse was eschatological because the computer was seen as involving matters of life and death.

At first, salvation was defined in narrowly mathematical terms. The new computer would "solve in a flash" problems that had "baffled men for years". By 1950, salvation had already become much more broadly defined. "Come the Revolution!" read the headline to a story about these new predictions. A broad and visionary ideal of progress was laid out: "Thinking machines will bring a healthier, happier civilization than any known heretofore". People would now be able to "solve their problems the painless electronic way". Airplanes, for example, would be able to reach their destinations "without one bit of help from the pilot".

By 1960, public discourse about the computer had become truly millennial. "A new age in human relations has opened," a reigning expert announced. Like all eschatological rhetoric, the timing of this promised salvation is imprecise. It has not yet occurred, but it has already begun. It is coming in five years or ten; its effects will be felt soon, the transformation is imminent. Whatever the timing, the end result is certain. "There will be a social effect of unbelievable proportions". "By surmounting the last great barrier of distance," the computer's effect on the natural world will be just as great. Most human labor will be eliminated, and people will finally be set "free to undertake completely new tasks, most of them directed toward perfecting ourselves, creating beauty, and understanding one another". The convictions were confirmed in still more sweeping tones in the late 1960s and early 1970s. The new computers had such "awesome power" that, as God was recorded in the book of Genesis, they would bring "order out of chaos". That "the computer age is dawning" was certain. One sign of this millennium will be that "the common way of thinking in terms of cause and effect [will be] replaced by a new awareness". That this was the stuff of which "dreams are made" cannot be denied. Computers would transform all natural forces. They would cure diseases and guarantee long life. They would allow everyone to know everything at all times. They would allow all students to learn easily and the best to learn perfectly. They would produce a world community and end war. They would overturn stratification and allow equality to reign. They would make government responsible and efficient, business productive and profitable, work creative, and leisure endlessly satisfying.

As for apocalypse, there was also much to say. Machines have always embodied not only the transcendental hopes but also the fear and loathing generated by industrial society. Regarding this new technological machine, Time once articulated this deep ambiguity in a truly gothic way. Viewed from the front, computers exhibit a "clean, serene dignity." This is deceptive, however, for "behind there hides a nightmare of pulsing, twitching, flashing complexity" Whereas contact with the sacred side of the computer is the vehicle for salvation, the profane side threatens destruction. It is something from which human beings must be saved. First, the computer creates the fear of degradation. "People are scared" because the computer has the power to "blot or diminish man". People feel "rage and helpless frustration".

Finally, there is the cataclysm, the final judgment on earthly technological folly that has been 
predicted from 1944 until the present day. Computers are "Frankenstein [monsters] which can ... wreck the very foundations of our society". They can lead to "disorders [that may] pass beyond control". There is a "storm brewing". There are "nightmarish stories" about the "light that failed". "Incapable of making allowances for error," the "Christian notion of redemption is incomprehensible to the computer". The computer has become the antichrist.

Alexander has taken the computer story to 1975 . This was the eve of the so-called personal computer, the very name of which demonstrates how the battle between human and antihuman continued to fuel the discourse that surrounded the computer's birth. In the decades of discussion that followed, utopian and antiutopian themes have remained prominent. Disappointment and "realism," however, also became more frequently expressed. Yet, even as computer news passed from the cover of Time to advertisements in the sports pages of daily newspapers, eschatological speculations about the Internet revolution and the new e-world have frothed to the bubbling surface of cultural life.

\subsection{Conclusions}

The main question in this paper is what is cultural meaning of Computer - As one of the newest and most powerful technological inventions of the modern age - from the perspective of Jeffrey Alexander?

The ambition of cultural sociology has been to open up this black box, to provide the internal architecture of social meaning via concepts of code, narrative and symbolic action, so that culture can finally assume its rightful place as equivalent to, and interpenetrated with, other kinds of structuring social force. Alexander has developed this internal architecture by incorporating and reinterpreting certain central aspects of the late Durkheim, phenomenology and micro-sociology, symbolic anthropology, structuralist semiotics, narratology, post-structuralism and deconstruction. Yet, even while elaborating the architecture of culture structure, Alexander has tried not to lose sight of the broader aim, which is to theorize society as a whole (Alexander, 2005: 22).

Reconstructing meaning is the very point of cultural sociology. Less concerned with material causality and demographics, its ambition is hermeneutical — to find deep underlying patterns, to trace the vectors of symbolic meaning and lines of interpretive force, and to make causal arguments about them. To demonstrate that there are coherent, if conflicting, subjectivities amid the buzzing and booming chaos of social reality is what cultural sociology is all about. Making wholes out of seemingly disconnected parts, what Dilthey describes as drawing the "hermeneutical circle," that is the method and the means (Alexander, 2010: 295)

For cultural sociology, the meanings of an event or phenomenon over time are created through three processes: a narrative form; symbolic coding and weighting. According to Alexander, computers were coded as good or sacred since its entry into the public sphere west and were presented the narratives from it. The computer would "solve in a flash" problems that had "baffled men for years". Thinking ma- chines will bring a healthier, happier civilization than any known heretofore. People would now be able to "solve their problems the painless electronic way" (salvation narrative). Most human labor will be eliminated, and people will finally be set "free to undertake completely new tasks, most of them directed toward perfecting ourselves, creating beauty, and understanding one another 
(eschatology narrative). Computers would bring order out of chaos. They would cure diseases and guarantee long life. They would allow everyone to know everything at all times. They would allow all students to learn easily and the best to learn perfectly. They would produce a world community and end war. They would overturn stratification and allow equality to reign. They would make government responsible and efficient, business productive and profitable, work creative, and leisure endlessly satisfying (Apocalypse narrative). However, as Heim (1993) indicates the well era of computer gradually ended and its dark side was broken on head of human and the romantic story with the computer showed its pathological aspects. Gradually the cultural meaning of computer was different in social life in the West and even was coded as aspect of evil. People seen the profane side threatens destruction. It is something from which human beings must be saved. In Print and digital media in the West 60s is cited that People are scared because the computer has the power to "blot or diminish man. Computers are "Frankenstein [monsters] which can wreck the very foundations of society. In 1966, the newspaper said that the computer has become the antichrist (Alexander, 2003: chapter 7).

According to Alexander (2010), although some experts believe that the media are independent, but in reality, they only gain autonomy and independence within culture. Even if media to be independent organizationally, but culturally. Sometimes there are different media and different social groups establish their own media. They pose their views and criticize the perspectives of rival media. But this is organizationally. Culturally, all media related to culture and social context affect them.

Social meanings have their own internal logic. Patterned by binary codes and temporal narratives, culture structures are as forceful, organized, and independent as social structures of a more material kind. When media product different programs and computers present services especially in internet, they evoke meanings and symbolic weight. They see themselves in terms of exemplary models that culture provides, and they wish to persuade audiences to view them in the same way. They gain authority by speaking on behalf of sacred values and against profane ones.

To understand media and computers, one must interpret and explain the structured meanings upon which media productions. The need to do so brings us right up to the edge of a truly cultural sociology.

Traditional approaches to meaning in sociology treat culture as a dependent variable; only social power, social structures, and material interests are treated as independent variables that have a causal status. In this manner, sociology turns from culture to its unmoved mover, "society" as a noncultural force. Modern culture still provides anchoring codes and narratives even if they often evoke rationality, individuality, skepticism, and social transformation more often than mystery, hierarchy, stasis, and metaphysical belief.

Computer has its own cultural language and language flows in other parts of life. Today, in Iran, the cultural language of computers has entered into other parts of life, even literature and we see stories and poems about computer and internet connection. This language was different at different times. As many of the phrases and terminology of computer and internet did not exist in the last 20 years, even today it is used in everyday language. For example, the couple's computer narrative: 
Man: Hi! I am log in! Woman: Did you buy that dress that I say? Man: Bad command or File name. Woman: But I am stressed, I tell you! Man: Syntax Error, Abort, Retry, Cancel! Woman: What did you pay? Man: File in Use, Read only, Try after some Time! Woman: So at least give me Bank ATM card! Man: Sharing Violation, Access Denied. Woman: You know, my marry with you is a wrong decision. Man: Data Type Mismatch! Woman: You're one of the useless. Man: By Default! Woman: So let's go out to eat something at least. Man: Hard Disk Full! Woman: Can you tell me what my role in life is? Man: unknown Virus Detected! Woman: and my mother? Man: Unrecoverable Error! Woman: and your relationship with your boss? Man: The only User with Write Permission! Woman: Did you love me more than or your computer? Woman: Too Many Parameters! Another issue which has been caused to feel computers present in our life is a computer language used in our everyday language. To clarify this issue, I would like to mention a few. Certainly all of us have encountered with such or similar cases in Farsi language: Hang, cancel, error, hard, user, add, web, search, delete, cut, copy, paste, save.

Seen, heard, and written down, symbolic languages externalize subjective meaning. These cultural forms can be interpreted and analyzed in a more rational and disciplined manner, though the experiences and sensibilities of social analysts necessarily continue to come into play. This so-called linguistic turn facilitated a broader "cultural turn" in the human sciences. Not only speech but also culture itself comes to be modeled as language: Binary symbols prestructure social action, as language does with speech. Meaning was studied as the wagging tail of social power, as resistance to hegemony, disguised governmentality, organizational isomorphism, cultural capital, or symbolic politics. As the cultural turn has broadened, more strongly cultural sociologies have finally emerged.

As Alexander (2003) studies social and political conflict and detects a dual discourse on purity of democracy and impurity of anti-democratic, we can consider a dual discourse about computer that computers are the symbol of good and solvent of many problems on the one hand and the symbol of evil and the cause of many problems on the other hand. This double discourse is formed through meaning-creation in mass media and to allow citizens to make judgments about computers.

Journalists, bloggers and audiences of computer form a dual discourse on the its positive aspects such as the beneficial aspects such as effective roles in education and scientific research, information, trade and industry, office equipment, and the power and politics and the negative and harmful aspects particularly issues such as pornography, creating skepticism in the principles, the impact of the Internet and computer games on children and adults, attacks and cyber-crimes, viruses, monitor on internet cafes, cybercrime and kinds of social harm, and etc. What they considered are symbolic definitions that make up this double discourse.

Aspects sacred and profane for computers are not argument on issues but are battle on stories and narratives that determines how people respond and react to the computer. Computers promise to change the social life, thus the heroic narratives form. Progressive narratives are drown plays that computer is known as a hero. It should be noted that there is no single attitude, structural codes and narrative discourse to computer at the community level. Computers and their practitioners try to offer justified face, though they create performances 
that their success depends on factors such as skill, luck, media Interpretations and responses of the audience. Computers use words, create metaphors and cover the rhetorical process. All these issues are pragmatic. Computers want to convince us about their good. If their performances are successful, we are persuaded. Whether we become convinced is less a matter of rightness in a moral or cognitive sense than aesthetic power.

In theory of cultural pragmatics, Alexander deconstructs social performance in terms of background representations, scripts, actors, means of symbolic production, mise en scène, social and interpretive power, and audiences. When felicitous performances fuse speaker and audience, these complex mediations became invisible, and audiences do not, in fact, see actions as if they are performed. We endow them with verisimilitude, so that scripted actions seem spontaneous and real. We believe that the words of politicians are true and their selves authentic. As societies become modern and more complex, however, the elements of performance become more separated one from another, and fusion becomes a much more difficult thing.

As the breadth of the use of computers, opportunities for direct communication between citizens and other matters correspondingly decrease. People are not face with computers but they face with media representations. The media have the ability to represent the computer as sacred or profane. Even if media to be independent organizationally, but culturally, not independent and dependent on social context and culture Different groups have their media, for example a variety of blogs made, each with different orientations and perspectives that each of them ads and criticize his rival views. Journalism constructs a vague and unpredictable cultural image between citizens and the computer. Today, television and online journalism de-construct computers.

Some scholars maintain that media interpretations continue to serve social power, whether that of capitalist classes, media owners, or the state. Once there was a golden age when media were independent and critical, but the once-proud media now caters to state power and private profit, its public function transformed into publicity, its truth giving way to propaganda. Other scholars are too critical by half, ignoring the media's increasing reflexivity vis-à-vis power. The other group wrongly identifies media skepticism with cynicism, suggesting as an alternative a rationalism that seems unrealistic and naive.

Media interpretations of events reflect historical time and place, not free-floating objective evaluations. The media do not provide a (biased) window on the world, so much as a set of resources through which everyday meanings and practices are constituted. News reports provide information, however, by telling stories, stringing independent observations into broader binary codes and narrative configurations. News reports present themselves as factual descriptions, yet they are culturally constructed symbolic representations at the same time. Journalism offers representation from a variety of public and collective viewpoints. Reporters make the hero in some codes and narratives of computers, which computer show up as fighting against its enemies.

\section{References}




\section{Ml Macrothink}

Journal of Sociological Research

ISSN 1948-5468

2014, Vol. 5, No.1

1. Alexander, J. and Smith, P. (2002) 'the Strong Program in Cultural Sociology: Elements of a Structural Hermeneutic', in Handbook of Sociological Theory, edited by Jonathan H. Turner. Kluwer Academic/ Plenum Publishers, New York.

2. Alexander, J. and Smith, P. (2010) 'the Strong Program origins, achievements, and prospects', in Handbook of Cultural Sociology, edited by John R. Hall, Laura Grindstaff and Ming- Cheng Lo, Published by Routledge.

3. Alexander, Jeffrey C. (2010). The Performance of Politics, Oxford University Press.

4. Alexander, Jeffrey C. and Philip Smith (1993): The Discourse of American Civil Society: A New Proposal for Cultural Studies', Theory \& Society 22(2): 151-207.

5. Alexander, Jeffry C. (2003): The Meanings of Social Life: A Cultural Sociology, Oxford University Press.

6. Alexander, Jeffry C. (2005): Why Cultural Sociology Is Not 'Idealist': A Reply to McLennan, "Theory Culture Society", 2005 22: 19, PP 19- 29.

7. Alexander, Jeffry C. (2007): The Meaningful Construction of Inequality and the Struggles Against It: A 'Strong Program' Approach to How Social Boundaries Change, Cultural Sociology 2007 1: 23.

8. Alexander, Jeffry C. (2008): Clifford Geertz and the Strong Program: The Human Sciences and Cultural Sociology, Cultural Sociology 2008 2: 157

9. Cordero, Rodrigo, Francisco Carballo and José Ossandón (2008): Performing Cultural Sociology A Conversation with Jeffrey Alexander, European Journal of Social Theory 11(4): 523-542

10. Coser, Lewis A (1971): Masters of Sociological thought, New York: Harcourt Brace Jovanovich, Inc.

11. Durkheim, Emile (1912): the elementary forms of religious life.

12. Geertz, C. (1999): A Life of Learning: Charles Homer Haskins Lecture for 1999. American Council of Learned Societies: Occasional Paper, No. 45.

13. Hall, John R., Mary Jo Neitz (1993): sociological perspectives.

14. Heim, Michael (1993): The metaphysics of virtual reality

15. Jalaeipour, Hamid reza and Jamal Mohammadi (2008): Contemporary theories of sociology, Ney publisher, Tehran.

16. Kalantari, Abdolhossein (2007): Meaning in sociology and cultural studies (comparison of two psychological and rule-oriented approaches), Journal of Social Sciences Faculty of Letters and Humanities Ferdowsi University of Mashhad, pages 101- 125.

17. Kurasawa, Fuyuki (2004): Alexander and the Cultural Refounding of American Sociology, Thesis Eleven, Number 79, November 2004: 53-64

18. McLennan, Gregor (2005): The 'New American Cultural Sociology' : An Appraisal, Theory Culture Society 2005 22: 1

19. Nabavi, Seyed Hosein (2012): Introduction to Cultural Sociology of Jeffrey Alexander, Unpublished.

20. Norton, Matthew (2011): A structural hermeneutics of The O'Reilly Factor, Theor Soc (2011) 40:315-346.

21. Ritzer, George (1967): Contemporary sociological theory, University of Maryland. 
22. Smith, Karl E. (2004): Further towards a sociology of evil, Thesis Eleven 2004 79: 65.

23. Trondman, Mats (2008): 'To Locate in the Tenor of Their Setting the Sources of Their Spell': Clifford Geertz and the 'Strong Program' in Cultural Sociology, Cultural Sociology Volume 2, Number 2: 201-221.

*** This paper extracted from PhD thesis with title: "The Cultural Meaning of Computer in Iranian's Social Life: from 2006 to 2013 AD” 